\title{
The effect of exogenous calcium on cucumber fruit quality, photosynthesis, chlorophyll fluorescence, and fast chlorophyll fluorescence during the fruiting period under hypoxic stress
}

Lizhong $\mathrm{He}^{1,2+}, \mathrm{Li} \mathrm{Yu}^{1,2+}$, Bin $\mathrm{Li}^{2,3}$, Nanshan Du ${ }^{2,4}$ and Shirong Guo ${ }^{2^{*}}$

\begin{abstract}
Background: Plants often suffer from hypoxic stress during waterlogging and hydroponic culturing. This study investigated the response of cucumber (Cucumis sativus L.) plant growth parameters, leaf photosynthesis, chlorophyll fluorescence, fast chlorophyll a fluorescence transient (OJIP), and fruit quality parameters to hypoxic stress alleviated by exogenous calcium. During the fruiting period, cucumber plants were exposed to hypoxia and hypoxia $+\mathrm{Ca}^{2+}$ treatment $\left(4 \mathrm{mM} \mathrm{Ca}^{2+}\right)$ for $9 \mathrm{~d}$.

Result: Exogenous calcium application enhanced the biomass and fruit quality of hypoxic stressed cucumber and also increased the net photosynthesis rate, stomatal conductance, intercellular $\mathrm{CO}_{2}$ concentration, maximum quantum efficiency of photosystem II photochemistry, actual photochemical efficiency of PSII, photochemical quenching coefficient, and non-photochemical quenching coefficient. Additionally, measurement of chlorophyll a fluorescence transients showed the positive K- and L-bands were more pronounced in leaves treated with hypoxia compared with those with hypoxia $+\mathrm{Ca}^{2+}$, indicating that hypoxic treatment induced uncoupling of the oxygenevolving complex and inhibited electron transport beyond plastoquinone pool $\left(\mathrm{Q}_{\mathrm{a}}, \mathrm{Q}_{\mathrm{b}}\right)$ including possible constraints on the reduction of end electron acceptors of photosystem I. Exogenous calcium can reduce these stress-induced damages in cucumber.

Conclusion: This research focused the effect of exogenous calcium on cucumber photosynthesis during the fruiting period under hypoxic stress. Hypoxic stress might impair the photosynthetic electron-transport chain from the donor side of PSII up to the reduction of end acceptors of PSI, and exogenous calcium enhanced electron transport capacity and reduced hypoxic damage of cucumber leaves.
\end{abstract}

Keywords: Cucumber, Exogenous calcium, Hypoxic stress, Photosynthesis, Chlorophyll fluorescence, Fast chlorophyll fluorescence

\footnotetext{
* Correspondence: srguo@njau.edu.cn

${ }^{+}$Lizhong He and Li Yu contributed equally to this work.

${ }^{2}$ Key Laboratory of Southern Vegetable Crop Genetic Improvement, Ministry

of Agricultural, College of Horticulture, Nanjing Agricultural University,

Nanjing 210095, China

Full list of author information is available at the end of the article
}

(c) The Author(s). 2018 Open Access This article is distributed under the terms of the Creative Commons Attribution 4.0 International License (http://creativecommons.org/licenses/by/4.0/), which permits unrestricted use, distribution, and reproduction in any medium, provided you give appropriate credit to the original author(s) and the source, provide a link to the Creative Commons license, and indicate if changes were made. The Creative Commons Public Domain Dedication waiver (http://creativecommons.org/publicdomain/zero/1.0/) applies to the data made available in this article, unless otherwise stated. 


\section{Background}

Land plants are often subjected to low oxygen concentrations in specific tissues during their development and in response to decreased environmental oxygen availability caused by waterlogging, flooding, and hydroponic culturing [1]. Approximately $16 \%$ of fertile land worldwide is affected by soil waterlogging, resulting in crop yield reductions of up to $80 \%$ [2]. Plants can survive in low oxygen $\left(\mathrm{O}_{2}\right)$ environments through the activation of diverse molecular, metabolic, and physiological responses [3], such as decreases in cellular energy change, a drop in cytoplasmic $\mathrm{pH}$, enhanced aerenchyma formation, stem elongation, the use of gas films around submerged leaves, and the accumulation of toxic end-products from anaerobic respiration and reactive oxygen species (ROS) [4, 5]. Plant growth, flash and dry matter accumulation are significantly depressed by root zone oxygen deficiency [6] Additionally, hypoxic stress can also destroy the ion transport processes, cell metabolism, and nutrient acquisition, through limits the supply of ATP to plant $\mathrm{H}^{+}$-ATPase pumps $[7,8]$.

Calcium, especially cytosolic free $\mathrm{Ca}^{2+}$, has been widely recognized as a key signal molecule in plants and is involved in multiple signal transduction pathways, which mediate plant adaptive responses to abiotic and biotic stimuli [9]. The involvement of calcium in hypoxia responses has been observed in many plants such as rice, wheat, and cucumber $[10,11]$. This hypoxia-mediated elevation of $\mathrm{Ca}^{2+}$ is fundamental for the activation of genes and synthesis of proteins required for acclimation responses at the cellular, tissue, and organismal levels [6, 12]. The complex processes of fruit growth and development are regulated by genes and metabolic pathways [13]. Photosynthetic carbon assimilation is a key plant metabolic process that is strongly influenced by environmental conditions [14]. Green plants need PSII to absorb energy from sunlight to support fruit development and ripening, but harnessing this tremendous light energy during photosynthesis carries great risk [15], especially when plants suffered from environmental stresses such as salinity [16] and heat stress [17].

Calcium is necessary for plant stress tolerance and proper photosynthetic function through maintaining the membrane stability, osmotic homeostasis and cell signaling [18]. Measuring chlorophyll fluorescence is a powerful and non-invasive technique to determine PSII activity. The abiotic and biotic factors have a significant effect on activity of PSII, so the measurement of PSII can give us a better understanding about plant responses to environmental change and the photosynthetic mechanisms [19]. The most common method is based on high-frequency records of PAM fluorometry emitted by dark-adapted leaves during short (usually one second long) pulses of strong actinic light by a fluorimeter [14].
Fluorescence kinetics can reflect some valuable information about photosynthesis, such as the photochemical efficiency and the function and structure of the photosynthetic electron transport, mainly in PSII [20]. The fluorescence value rises from the initial $\left(\mathrm{F}_{0}\right)$ to the maximal $\left(F_{m}\right)$ in seconds and can be separated into $\mathrm{O}$, J, $\mathrm{I}$ and $\mathrm{P}$ phase. The JIP-test, as a mathematical model of the polyphasic transient fluorescence [14], enables measurement of some biophysical parameters and probabilities characterizing the functional and structural attributes of components involved in PSII. Previous reviews had reported that the $\mathrm{Ca}^{2+}$ signals contribute to red light, blue light, UV-B signaling and circadian clock of plant [21]. It was hypothesized exogenous calcium application would be associated increased photosynthesis, larger fruits, increased chlorophyll parameters.

Cucumber, one of the largest vegetable crops globally in terms of production, is an economically important vegetable crop and is sensitive to hypoxic stress. Previous studies have demonstrated that exogenous putrescine and 24-epibrassinolide improved the photosynthetic performance of cucumber under salt [16] and $\mathrm{Ca}\left(\mathrm{NO}_{3}\right)_{2}$ stress [22], respectively. Examples of the application of fast chlorophyll fluorescence kinetics can also be found in citrus [23], maize, and tomato [14, 24]. However, no studies have yet combined the determination of photosynthetic characteristics with the chlorophyll fluorescence of cucumber under hypoxic stress. Therefore, the aim of this work was to clarify the effect of exogenous calcium on the improvement of photosynthetic performance and fast chlorophyll fluorescence records in fruiting cucumber plants under hypoxic stress.

\section{Methods}

\section{Plant materials and growth conditions}

Cucumber (Cucumis sativus L. cv. Jinchun No. 2, hypoxia-sensitive [25]) were sown in plastic trays $(41 \times$ $41 \times 5 \mathrm{~cm})$ containing quartz sand, and cultured in a greenhouse $\left(32^{\circ} 02^{\prime} \mathrm{N}, 118^{\circ} 46^{\prime} \mathrm{E}\right.$, Nanjing, China) at $25^{\circ}$ $\mathrm{C}-30{ }^{\circ} \mathrm{C}$ (day) and $15{ }^{\circ} \mathrm{C}-18{ }^{\circ} \mathrm{C}$ (night) under natural light (maximum photosynthesis photon flux density (PPFD) about $1200 \mu \mathrm{mol} \mathrm{m} \mathrm{m}^{-2} \mathrm{~s}^{-1}$ ) with relative humidity $(\mathrm{RH})$ from 70 to $85 \%$. Treatments consisted of [8]: 1) Control: half-strength Hoagland solution (containing $2 \mathrm{mM} \mathrm{Ca}^{2+}$ ) with a dissolved oxygen (DO) level of $8.0 \pm$ $0.2 \mathrm{mg} \mathrm{L}^{-1}$; 2) Hypoxia treatment: half-strength Hoagland solution (containing $2 \mathrm{mM} \mathrm{Ca}^{2+}$ ) with a DO level of $1.0 \pm 0.1 \mathrm{mg} \mathrm{L}^{-1}$ that was prepared by pumping $\mathrm{N}_{2}$ gas into the nutrient solutions; 3) Hypoxia $+\mathrm{CaCl}_{2}$ treatment: half-strength Hoagland solution $+4 \mathrm{mM}$ $\mathrm{CaCl}_{2}$ with a DO level of $1.0 \pm 0.1 \mathrm{mg} \mathrm{L}^{-1}$ and the oxygen concentration in the nutrient solution controlled as in the hypoxia treatment. The oxygen concentration in the nutrient solutions was monitored with an automatic 
DO control system (Quantum-25, Quantum Analytical Instruments Inc., USA). Every treatment had 18 plants with 3 replicates, and the experimental treatments started when second female flowers of cucumber plants finished fruit setting.

Following $9 \mathrm{~d}$ of treatment, the shoots, roots, and fruit of the control and treated plants were harvested, immediately frozen in liquid nitrogen, and stored at $-80{ }^{\circ} \mathrm{C}$ for further analysis. Photosynthetic characteristics and chlorophyll a fluorescence transient was measured as indicated below before plants were destructively harvested.

\section{Measurements of biomass and the quality of cucumber fruits}

Plant height, stem diameter, and fruit weight were determined using a ruler, Vernier caliper, and electronic scale, respectively. To determine the fresh weight of stems and roots, the plants were washed with distilled water and weighed after wiping off the water. Fruit soluble protein was measured according to Bradford [26]. Fruit $\mathrm{Ca}^{2+}$ content was measured using the Calcium Colorimetric Assay Kit (Bio Vision, Mountain View, CA, USA) following the manufacturer's instructions [8]. The total soluble solids content (TSS, in ${ }^{\circ} \mathrm{Brix}$ ), the titratable acidity (TA, milliequivalents of acid per $100 \mathrm{~g}$ of fresh matter) and total soluble sugars of cucumber fruits were assayed in according to Kang et al. [27].

\section{Measurement of gas-exchange parameters}

The net photosynthetic rate $\left(P_{\mathrm{n}}\right)$, stomatal conductance $\left(g_{\mathrm{s}}\right)$, intercellular $\mathrm{CO}_{2}$ concentration $\left(C_{\mathrm{i}}\right)$, and transpiration rate $\left(T_{\mathrm{r}}\right)$ of the third fully expanded leaf from the shoot tip were monitored using a portable photosynthesis system (Li-6400; LI-COR, Inc., Lincoln, NE, USA) at 10:30 am after $9 \mathrm{~d}$ of treatments. Cuvette conditions were maintained at a photosynthetic photon flux density (PPFD) of $1000 \mu \mathrm{mol}$ photons $\mathrm{m}^{-2} \mathrm{~s}^{-1}$, relative humidity at $60-70 \%$, leaf temperature of $25{ }^{\circ} \mathrm{C}$, and external $\mathrm{CO}_{2}$ concentration of $380 \pm 10 \mu \mathrm{mol} \mathrm{mol}^{-1}$. Water use efficiency (WUE) was calculated as WUE $=P_{\mathrm{n}} / T_{\mathrm{r}}$.

\section{Analysis of chlorophyll fluorescence}

Chlorophyll fluorescence imaging of cucumber leaves was performed using an imaging-PAM fluorometer (Walz, Effeltrich, Germany). Leaves were placed in darkness for $30 \mathrm{~min}$ prior to measurement. Maximum quantum yield of PSII (Fv/Fm), actual photochemical efficiency of PSII (ФPSII), photochemical quenching coefficient (qP), and non-photochemical quenching coefficient $\left(\mathrm{NPQ}\left(=\mathrm{Fm} / \mathrm{Fm}^{\prime}-1\right)\right)$ were measured and calculated in according to Lu et al. [28] and Yuan et al. [16]. The PAM software selected the same areas of each leaf for the fluorescence image.

\section{Measurement of chlorophyll a fluorescence transients}

Chlorophyll a fluorescence (OJIP) transients were measured using a Handy Plant Efficiency Analyzer (Handy-PEA, Hansatech Instruments Ltd., Norfolk, UK) according to the method of Strasserf and Srivastava [29]. All measurements were done with plants that had been dark-adapted for $3 \mathrm{~h}$ at room temperature $\left(22-25{ }^{\circ} \mathrm{C}\right)$. Transient fluorescence was induced by approximately $2000 \mu \mathrm{mol} \mathrm{m} \mathrm{m}^{-2} \mathrm{~s}^{-1}$ red light provided by an array of three light-emitting diodes (peak $650 \mathrm{~nm}$ ) that focused on the leaf surface to give homogenous illumination over the exposed area of the leaf ( $4 \mathrm{~mm}$ in diameter). Data were sampled at $10 \mu \mathrm{s}$ intervals for the first $300 \mu \mathrm{s}$, providing excellent time resolution of $F_{O}$ and the initial rise kinetics. The time resolution of digitization was then switched to slower acquisition rates as the kinetics of the fluorescence signal slowed.

OJIP transient was analyzed according to the JIP-test formulae $[23,30]$. The fluorescence intensity at $20 \mu$ s (considered to be minimum fluorescence F0); maximal fluorescence intensity equal to $\mathrm{Fm}$ as the intensity was high enough to ensure the closure of all reaction centers (RCs) of PSII; and fluorescence intensity at $300 \mu \mathrm{s}(\mathrm{F} 300 \mu \mathrm{s}), 2 \mathrm{~ms}$ (J-step, FJ), and $30 \mathrm{~ms}$ (I-step, FI) [30]. The following parameters that all refer to time 0 (start of fluorescence induction) are: (a) the specific energy fluxes (per reaction center, $\mathrm{RC}$ ) for absorption $(\mathrm{ABS} / \mathrm{RC})$, trapping $\left(\mathrm{TR}_{\mathrm{o}} / \mathrm{RC}\right)$, electron transport $\left(\mathrm{ET}_{\mathrm{o}} /\right.$ $\mathrm{RC}$ ), and dissipation at the level of the antenna chlorophylls $\left(\mathrm{DI}_{\mathrm{o}} / \mathrm{RC}\right)$ and $(\mathrm{b})$ normalized total complementary area above the OJIP transient or total electron carriers per RC $\left(\mathrm{Sm}=\mathrm{EC}_{0} / \mathrm{RC}=\mathrm{Area} /\left(\mathrm{F}_{\mathrm{m}}-\mathrm{F}_{0}\right)\right)$. Approximated initial slope of the fluorescence transient $f(\mathrm{t}): \mathrm{M}_{0}=4 \mathrm{M}_{\mathrm{o}}=4 \cdot\left(\mathrm{F}_{300 \mu \mathrm{s}}-\mathrm{F}_{0}\right) /$ $\left(\mathrm{F}_{\mathrm{m}}-\mathrm{F}_{\mathrm{o}}\right)$. Performance index (PI) on absorption basis $\mathrm{PI}_{(\mathrm{abs})}$ $=(\mathrm{RC} / \mathrm{ABS}) \cdot\left[\phi \mathrm{P}_{\mathrm{o}} /\left(1-\phi \mathrm{P}_{\mathrm{o}}\right)\right]\left[\psi_{\mathrm{o}} /\left(1-\psi_{\mathrm{o}}\right)\right]$. Maximum quantum yield of primary photochemistry: $\phi \mathrm{P}_{\mathrm{o}}=\mathrm{F}_{\mathrm{v}} / \mathrm{F}_{\mathrm{m}}$ $=\left(\mathrm{F}_{\mathrm{m}}-\mathrm{F}_{\mathrm{o}}\right) / \mathrm{F}_{\mathrm{m}}$.

Extended analysis of OJIP transients was done by calculating the relative variable fluorescence: $V_{t}=\left(F_{t}-F_{o}\right) /$ $\left(\mathrm{F}_{\mathrm{m}}-\mathrm{F}_{\mathrm{o}}\right), \mathrm{W}_{\mathrm{K}}=\left(\mathrm{F}_{\mathrm{t}}-\mathrm{F}_{\mathrm{o}}\right) /\left(\mathrm{F}_{300 \mu \mathrm{s}}-\mathrm{F}_{\mathrm{o}}\right)$ and the differences between the treated and control samples. The $\Delta \mathrm{L}-, \Delta \mathrm{K}$ and $\Delta \mathrm{J}$-bands appear around 130,300 , and $2 \mathrm{~ms}$, respectively, and are associated with the ungrouping of PSII units, the uncoupling of the oxygen-evolving complex (OEC), and the accumulation of $\mathrm{Q}_{\mathrm{A}}{ }^{-}$[23].

\section{Statistical analysis}

Experimental data were processed with SAS software (SAS Institute, Cary, NC, USA) using Duncan's multiple range test at the $p<0.05$ level of significance.

\section{Results}

Morphological parameters and the quality of fruit

Plant height, stem diameter, and fresh weight of shoot and root decreased significantly under hypoxic treatment $(p=$ 0.05 ), especially root fresh weight (Table 1 ). Plant weight, 
Table 1 Effect of exogenous calcium on biomass of cucumber at fruiting period under hypoxia stress

\begin{tabular}{lllll}
\hline Treatment & Plant height $(\mathrm{cm})$ & Stem diameter $(\mathrm{mm})$ & Fresh weight of shoot $\left(\mathrm{g} \mathrm{plant}^{-1}\right)$ & ${\text { Fresh weight of root }\left(\mathrm{g} \mathrm{plant}{ }^{-1}\right)}$ \\
\hline Control & $127.43 \pm 1.78 \mathrm{a}$ & $14.11 \pm 1.12 \mathrm{a}$ & $244.95 \pm 19.06 \mathrm{a}$ & $88.73 \pm 1.46 \mathrm{a}$ \\
Hypoxia & $104.33 \pm 2.07 \mathrm{c}$ & $11.29 \pm 0.29 \mathrm{~b}$ & $171.06 \pm 25.65 \mathrm{~b}$ & $45.33 \pm 5.92 \mathrm{C}$ \\
Hypoxia $+\mathrm{Ca}^{2+}$ & $115.96 \pm 3.92 \mathrm{~b}$ & $12.72 \pm 0.51 \mathrm{ab}$ & $216.31 \pm 12.35 \mathrm{a}$ & $60.44 \pm 8.85 \mathrm{~b}$ \\
\hline
\end{tabular}

Each value is the mean \pm SE of three independent experiments. Different letters indicate significant differences within columns at $p=0.05$, according to Duncan's multiple range test

stem diameter, and shoot and root fresh weight were $18 \%$ to $49 \%$ of the control. Conversely, exogenous calcium alleviated hypoxic stress-induced inhibition of growth, but exogenous calcium exerted no effect on stem diameter.

Fresh weight of fruit was inhibited by hypoxic treatment compared to control treatment $(p=0.005)$, and was higher in the hypoxia $+\mathrm{CaCl}_{2}$ treatment compared to the hypoxic treatment (Fig. 1). Although the fresh weight, total protein content, and $\mathrm{Ca}^{2+}$ content of fruit decreased under hypoxic treatment, total soluble solids content and soluble sugar concentrations tended to increase (Table 2). Titratable acidity (TA) showed no significant change compared with the control treatment. After treatment with exogenous calcium, fresh weight, $\mathrm{Ca}^{2+}$ content, titratable acidity, and soluble sugar concentrations increased markedly when compared with the hypoxic treatment (Table 2).

\section{Gas exchange parameters}

Hypoxic stress reduced $P_{\mathrm{n}}, g_{\mathrm{s}}$, and $C$ i to 18 to $47 \%$ of control levels (Fig. 2). However, hypoxia-induced negative effects were significantly diminished by exogenous calcium; this increased $P_{\mathrm{n}}, g_{\mathrm{s}}$, and $C_{\mathrm{i}}$ by 51 to $119 \%$, compared with the hypoxic treatment, but did not result in recovery to control levels. WUE did not differ significantly between treatments.

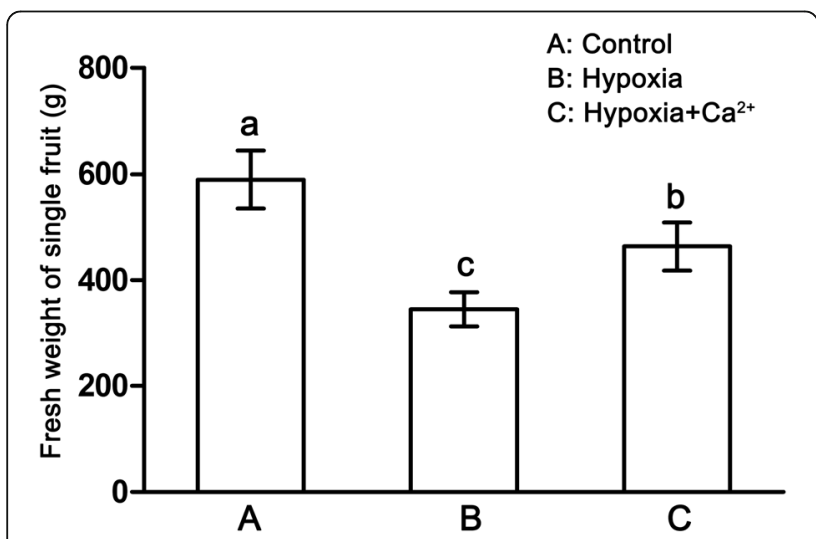

Fig. 1 The fresh weight of single fruit of cucumber plants under normoxic conditions (a), hypoxic treatments $(\mathbf{b})$ and hypoxia $+\mathrm{Ca}^{2+}$ treatments $(\mathbf{c})$. Values are means \pm SE of three independent experiments. Bars marked with different letters are significantly different from each other according to Duncan's multiple range test $(p=0.05)$

\section{Chlorophyll fluorescence}

Compared with the control, hypoxic treatment significantly decreased $\mathrm{Fv} / \mathrm{Fm}$, ФPSII, qP, and NPQ (=Fm/Fm '-1). Fv/Fm, ФPSII, qP, and NPQ (=Fm/Fm' -1$)$ were 81.5 to $57.5 \%$ of control levels (Fig. 3). Conversely, application of exogenous calcium increased the level of these parameters when compared with the hypoxic treatment $(p=$ 0.05). Respective pseudo-color images of leaves indicated the status of the four parameters under different treatments (Fig. 3). The values of Fv/Fm, ФPSII, qP, and NPQ $\left(=\mathrm{Fm} / \mathrm{Fm}^{\prime}-1\right)$ across the leaf surface decreased unevenly under hypoxia. $\mathrm{Fv} / \mathrm{Fm}$ and NPQ (=Fm/Fm'-1) near the veins decreased significantly compared with the control. Exogenous calcium could recover the color of leaves almost to the level of the controls.

\section{Leaf chlorophyll a fluorescence (OJPI) transients and related parameters}

All treatments displayed a typical polyphasic increase in OJIP transient, including the O, J, I, and P phases (Fig. 4). Hypoxic stress induced the OJIP transients with a rise at J-step and I-step, but a significant depression at P-step.

The OJIP transient presented in Fig. $5 \mathrm{a}$ and $\mathrm{b}$ shows differences in variable fluorescence curves $\Delta \mathrm{V}_{\mathrm{t}}$ and $\Delta \mathrm{W}_{\mathrm{k}}$, respectively. There are three distinct trends: i) an increase in the $\Delta \mathrm{K}$-band $(300 \mu \mathrm{s})$, ii) An increase in the $\Delta \mathrm{J}$-band ( $2 \mathrm{~ms})$, and iii) an increase in the $\Delta \mathrm{I}$-band $(30 \mathrm{~ms})$ (Fig. $5 \mathrm{a})$. The positive $\Delta \mathrm{K}$-band, $\Delta \mathrm{J}$-band, and $\Delta \mathrm{I}$-band were more pronounced in hypoxic stressed leaves than in those treated with exogenous calcium. There is a clear $\Delta \mathrm{L}$-band that was more pronounced in hypoxic leaves than in exogenous calcium-treated ones (Fig. 5b).

Compared with controls, hypoxic stressed leaves had significant increases in dissipated energy per $\mathrm{RC}\left(\mathrm{DI}_{0} /\right.$ $\mathrm{RC})$, trapped energy flux per $\mathrm{RC}\left(\mathrm{TR}_{0} / \mathrm{RC}\right)$, and absorption flux per RC (ABS/RC) (Fig. 6). Hypoxic stress also decreased total electron carriers per reaction center $\left(\mathrm{S}_{\mathrm{m}}\right)$, suggesting that the probability of electron transport beyond $\mathrm{Q}_{\mathrm{A}}^{-}$was decreased (Fig. 6). This condition finally induced the increased maximum reduction speed of $\mathrm{Q}_{\mathrm{A}}{ }^{-}\left(\mathrm{M}_{0}\right)$ and decreased the dissipated energy flux per $\mathrm{RC}\left(\mathrm{DI}_{0} / \mathrm{RC}\right)$, maximum yield of primary photochemistry of PSII $(\mathrm{Fv} / \mathrm{Fm})$, and performance index on absorption basis $\left(\mathrm{PI}_{\mathrm{abs}}\right)$. After applying the exogenous calcium, these performance parameters recovered to control levels (Fig. 6). 
Table 2 The effect of exogenous calcium on fruit quality of cucumber under hypoxia stress

\begin{tabular}{lllll}
\hline Treatment & Protein content $\left(\mathrm{mg} \mathrm{g}^{-1} \mathrm{FW}\right)$ & Soluble solids & Titratable acidity (\%) & Total soluble sugar (\%) \\
\hline Control & $589.78 \pm 54.45 \mathrm{a}$ & $2.53 \pm 0.49 \mathrm{~b}$ & $0.067 \pm 0.006 \mathrm{~b}$ & $0.535 \pm 0.084 \mathrm{c}$ \\
Hypoxia & $345.05 \pm 32.57 \mathrm{~b}$ & $3.55 \pm 0.61 \mathrm{a}$ & $0.052 \pm 0.011 \mathrm{~b}$ & $0.814 \pm 0.142 \mathrm{~b}$ \\
Hypoxia+Ca ${ }^{2+}$ & $463.58 \pm 45.53 \mathrm{ab}$ & $2.63 \pm 0.15 \mathrm{ab}$ & $0.093 \pm 0.015 \mathrm{a}$ & $1.886 \pm 0.068 \mathrm{a}$ \\
\hline
\end{tabular}

Each value is the mean \pm SE of three independent experiments. Different letters indicate significant difference at $p=0.05$, according to Duncan's multiple range test

\section{Discussion}

Molecular oxygen is involved in a wide variety of plant biochemical reactions. It has also been well documented that plants may reduce their growth, yield, and photosynthetic efficiency as an avoidance strategy in response to a variety of stresses $[16,22,31]$. Thus, studying the response of cucumber plants at fruiting stage to hypoxic stress may help us to understand the mechanisms underlying cucumber hypoxic tolerance. In the present work, hypoxic stress significantly suppressed the growth and photosynthesis of cucumber plants (Table 1, Fig. 2) and reduced cucumber fruit fresh weight (Fig. 1). Exogenous calcium enhanced the growth, photosynthesis and fruit quality of hypoxic stressed cucumbers.

It is widely accepted that phloem transport is inhibited by hypoxia; this is probably caused by decreased sugar importing or reloading into phloem resulting from energy deprivation in the tissues [32]. Kang et al. [27] found that the total soluble and starch content of cucumber leaves increased significantly under hypoxic stress because of decreased sugar transport from leaves to roots. Our previous study also found that root-zone hypoxic stress decreased the biomass of plants and soluble protein of leaves [33]. We obtained similar results in cucumber fruit in the current study. Hypoxia reduced the soluble protein and $\mathrm{Ca}^{2+}$ content of cucumber fruit but increased the soluble solids and total soluble sugar (Table 2). After extra $\mathrm{Ca}^{2+}$ was added to the nutrient solution, the above indexes approached control levels, indicating that exogenous $\mathrm{Ca}^{2+}$ may alleviate hypoxic stress in cucumber plants.

Reduced $\mathrm{CO}_{2}$ assimilation is a common response to stress conditions that occurs as a result of stomatal closure and causes further damage to the photosynthetic apparatus. In this work, hypoxia caused a reduction of $P_{\mathrm{n}}$, $g_{\mathrm{s}}$, and $C_{\mathrm{i}}$ in cucumber plants (Fig. 2). The simultaneous decreases in $g_{\mathrm{s}}$ and $C_{\mathrm{i}}$ indicate stomatal closure is limiting photosynthesis by limiting access to $\mathrm{CO}_{2}$ in the leaf. Conversely, exogenous calcium caused significant increases in $P_{\mathrm{n}}, g_{\mathrm{s}}$, and $C_{\mathrm{i}}$ (Fig. 2). Exogenous calcium improved the photosynthetic capacity by enhancing the carbon assimilation capacity of leaves and by regulating stomatal movement under hypoxic stress.
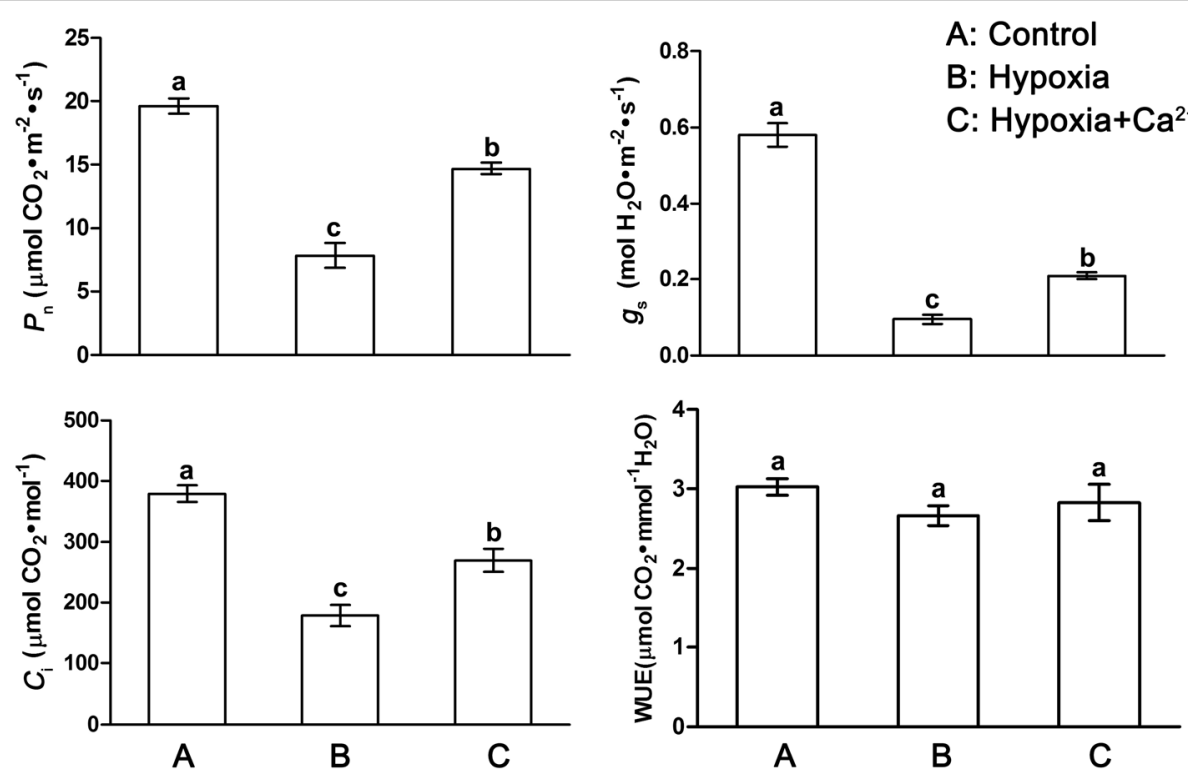

Fig. 2 Effect of exogenous $\mathrm{Ca}^{2+}$ on gas exchange parameters in leaves of cucumber under normoxic conditions (a), hypoxic treatments (b) and hypoxia $+\mathrm{Ca}^{2+}$ treatments $(\mathbf{c})$. Values are means \pm SE of three independent experiments. Bars marked with dissimilar letters are significantly different from each other according to Duncan's multiple range tests $(p<0.05)$. $P_{\mathrm{n}}$, net photosynthetic rate; $g_{\mathrm{s},}$ stomatal conductance; $C_{\mathrm{i}}$ intercellular $\mathrm{CO}_{2}$ concentration; WUE, water use efficiency 


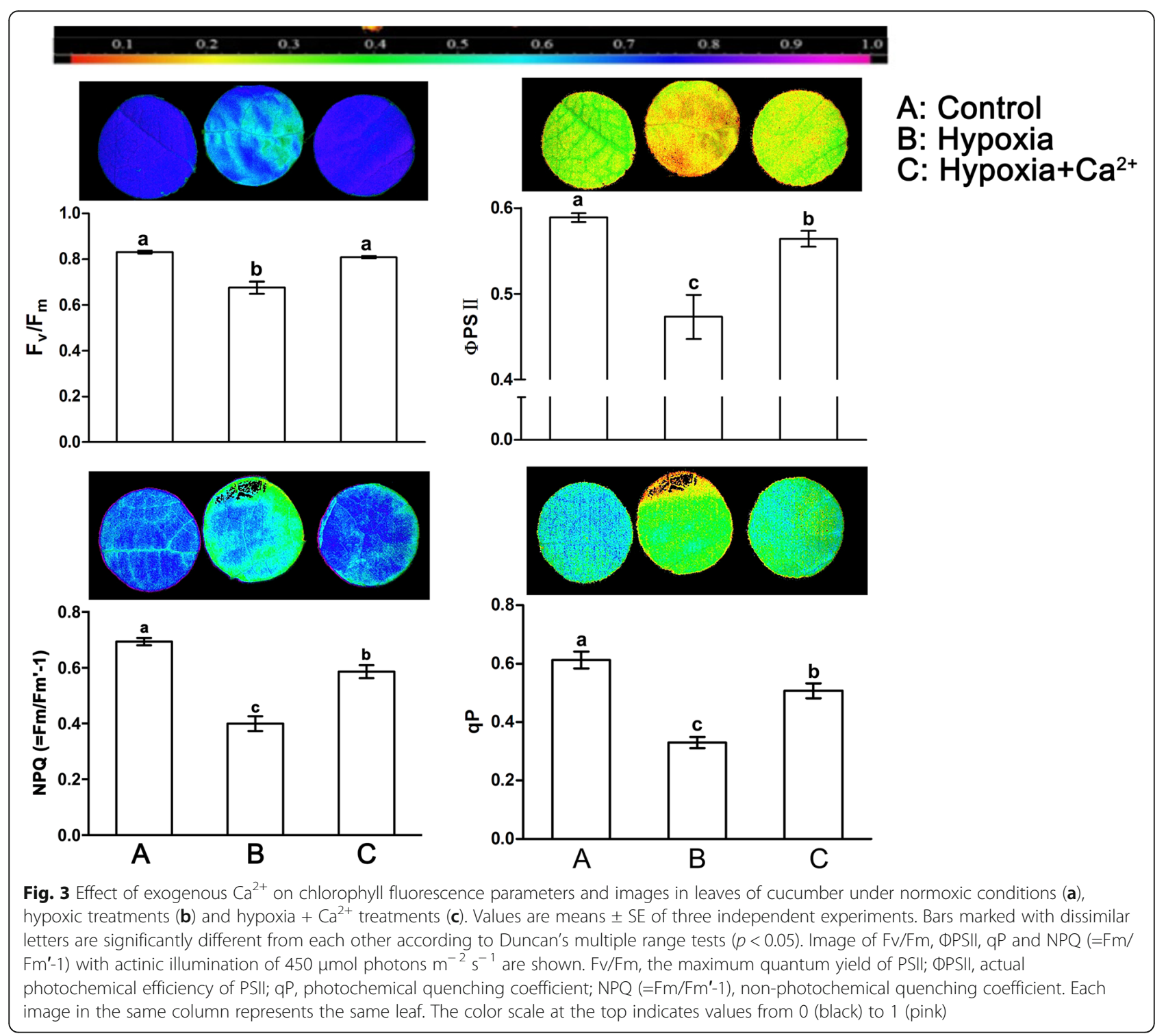

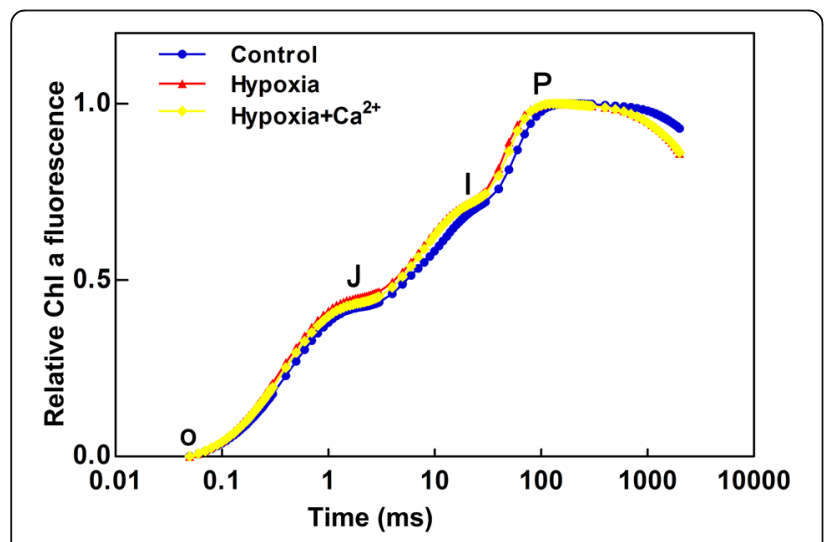

Fig. 4 Fast chl a fluorescence transient (OJP) plotted on logarithmic time scale $(0.01-1 \mathrm{~s})$ measured under normoxic conditions (Control), hypoxic treatments (Hypoxia), hypoxia $+\mathrm{Ca}^{2+}$ treatments $\left(\mathrm{Hypoxia} \mathrm{Ca}^{2+}\right.$ )
In leaf studies, it is natural to extend the interpretation of chlorophyll fluorescence data to analyze its impact on photosynthetic rates of $\mathrm{CO}_{2}$ assimilation [18]. Imaging of chlorophyll fluorescence is becoming increasingly popular as a screening and diagnostic tool [34] and can enhance our understanding of photosynthetic heterogeneity arising from patchy responses of stomata and distributed metabolic regulation [35]. This method can also overcome the disadvantages of conventional chlorophyll fluorescence analysis based on point measurements. Hypoxia, like other abiotic stress, caused injuries across the whole leaf generally, and then decreased the photosynthetic capacity of the injured areas of leaves. To quantify the photosynthetic capacity of stressed cucumber leaves under dark-adapted and light-adapted conditions, we measured $\mathrm{Fv} / \mathrm{Fm}$ and ФPSII, respectively [35]. Our results showed that $\mathrm{Fv} / \mathrm{Fm}$ and ФPSII were reduced under hypoxic treatment (Fig. 3), suggesting 


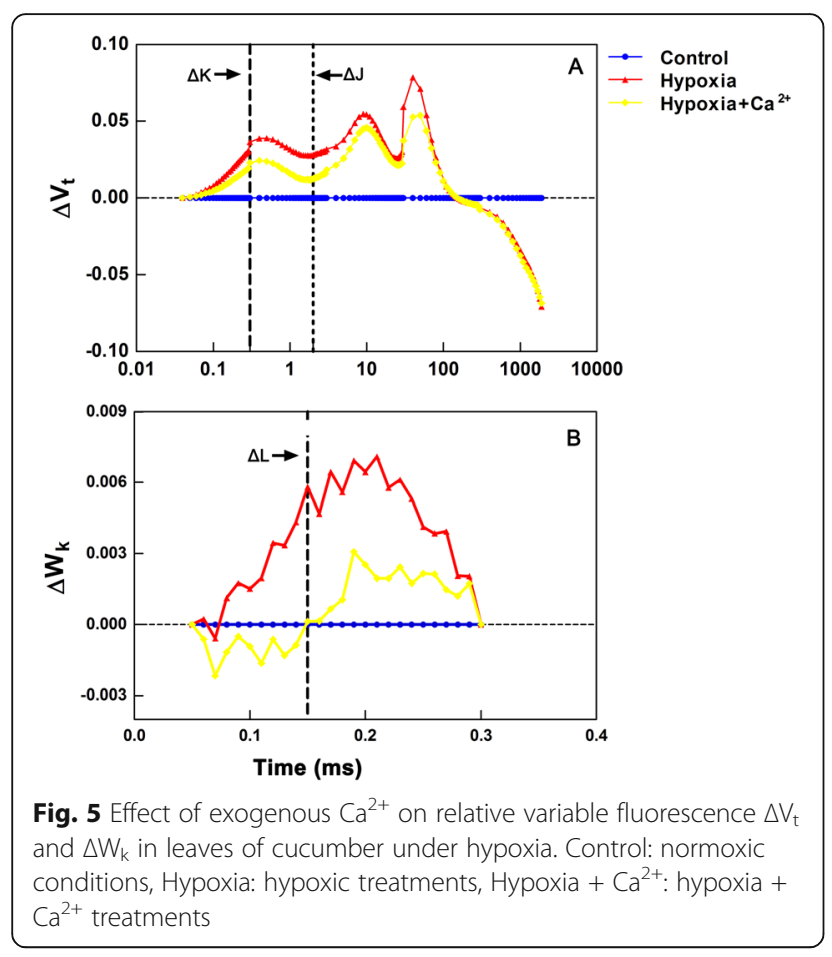

that electron transfer from the primary acceptor plastoquinone $\left(\mathrm{Q}_{\mathrm{A}}\right)$ to the secondary acceptor plastoquinone $\left(\mathrm{Q}_{\mathrm{B}}\right)$ at the acceptor side of PSII was blocked under stress condition [36]. However, exogenous calcium significantly enhanced Fv/Fm and ФPSII under stressed condition, indicating that exogenous calcium alleviated the photo-inhibition and improved the photochemical efficiency of stressed cucumber plants [37]. Additionally, exogenous calcium treatments also increased the non-photochemical quenching coefficient (NPQ (=Fm/Fm'-1)) and the photochemical quenching (qP) of hypoxic plants. This result further suggests that exogenous calcium could alleviate inhibition of the photochemical efficiency of cucumber by regulating the capacity of the heat-dissipation pathway, thereby reducing the negative impacts of hypoxic stress on the photosynthetic capacity of cucumber plants [38].

To understand the effect of different environmental stresses on photosynthesis, the measurement and analysis of fast chlorophyll a fluorescence is a useful and efficient method for the assessment of many external or intrinsic adverse effects on PSII photochemistry $[39,40]$, although the OJIP test renains a controversial interpretation. The typical polyphasic transient is changed under hypoxic stress (Fig. 4) and the positive

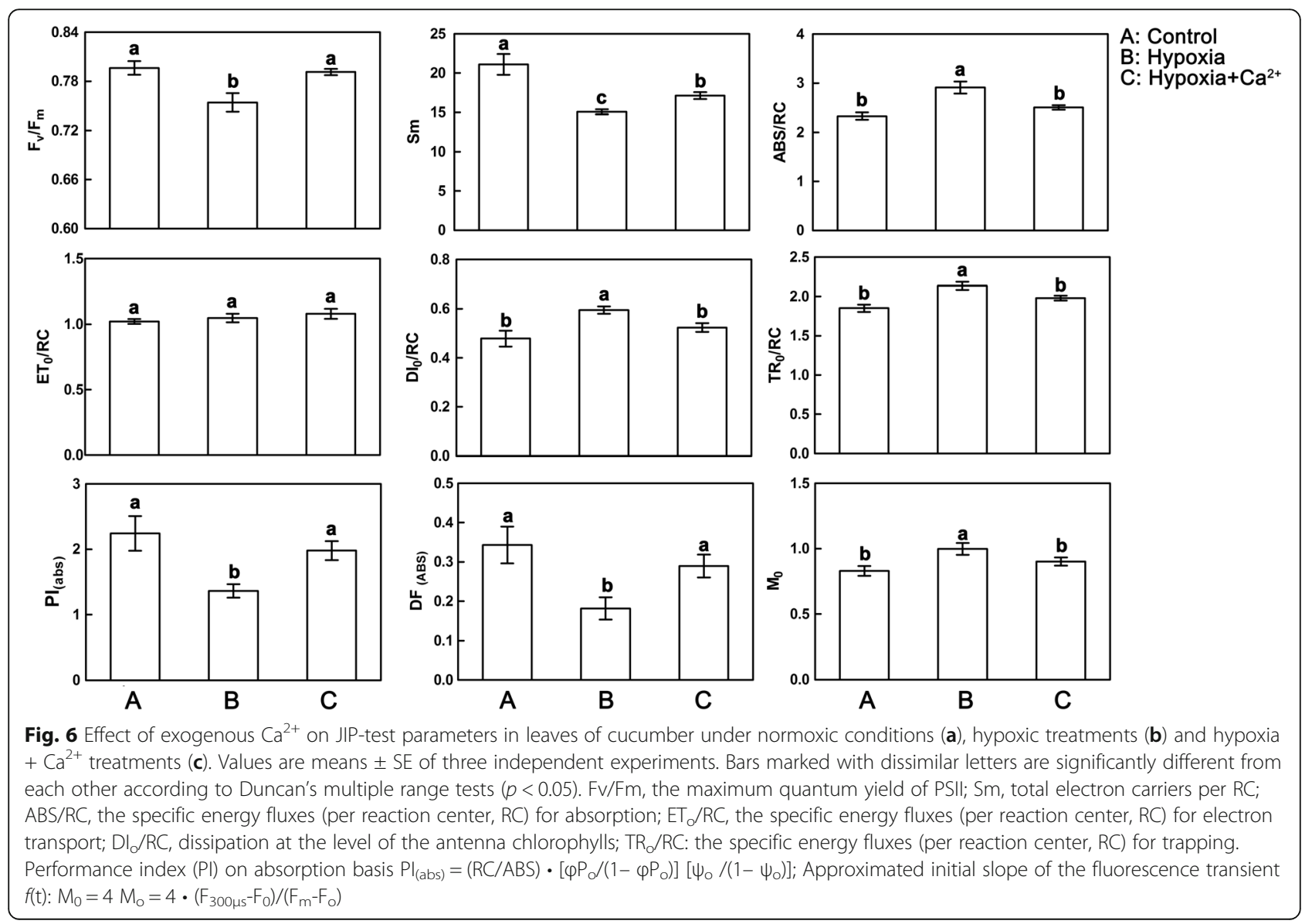


$\Delta \mathrm{K}$-bands, $\Delta \mathrm{J}$-bands, and $\Delta \mathrm{I}$-bands appear after illumination (Fig. 5). Previous studies indicated that the $\Delta \mathrm{K}$-bands and $\Delta \mathrm{J}$-bands are associated with uncoupling of the OEC and the accumulation of $\mathrm{Q}^{-}$(i.e. inhibition of the re-oxidation of $\mathrm{Q}_{\mathrm{a}}{ }^{-}$), respectively [24]. The efficient of the OEC $\left(\mathrm{F}_{\mathrm{v}} / \mathrm{F}_{0}\right)$ is the most sensitive component of photosynthetic electron transport [39]. The appearance of positive $\Delta \mathrm{K}$-bands in the fluorescence transients of stressed plants might indicate the OEC was damaged and the energetic connectivity between photosynthetic units was altered under hypoxic conditions [41]. The finding that the positive $\Delta \mathrm{K}$-bands were less pronounced in exogenous calcium-treated leaves than in hypoxic stressed ones might indicate the OEC was less damaged in the former than in the latter. The positive $\Delta \mathrm{I}$-bands (Fig. 5a) under hypoxic stress may suggested that hypoxia destroyed the acceptor side of PSII more severely than the donor side of PSII; the inactivation of the acceptor side might indicate the damaged of electron transport, according to previous studies [42]. Based on the Grouping Concept and JIP-test [40], the hypoxia-induced positive $\Delta \mathrm{I}$-bands (Fig. 5b) meant that the PSII units were destroyed into less grouped, then less electron and energy were being transported inside or between the PSII units. As the grouped conformation of PSII is more stable than the ungrouped one, the decreased grouping caused by hypoxic stress suggested that the stability of PSII units in stressed cucumber leaves had been lost and the PSII units became more fragile. As showed in Fig. 5, our study supported that the heterogeneity of the OJIP test was increased under hypoxic treatment.

In this study, the decrease in the fraction of active $\mathrm{RCs}$ (estimated as an increase of $\mathrm{ABS} / \mathrm{RC}$ ) was observed in hypoxic stressed plants (Fig. 6). The inactivated fraction of $\mathrm{RCs}$ or the increased apparent antenna size will lead to a decrease of this parameter. Accumulation of inactive $\mathrm{RCs}$ is related to the increased efficiency of absorbed light dissipation as heat $\left(\mathrm{DI}_{0} / \mathrm{RC}\right)$ (Fig. 6), indicating a higher level of the non-photochemical de-excitation process. To protect stressed leaves from photo-oxidative damage, plants disspute the excess absorbed light energy as heat. As indicated by decreases in the total performance index $\left(\mathrm{PI}_{(\mathrm{abs})}\right)$, hypoxic stressed leaves had decreased $\mathrm{Sm}$ and $\mathrm{DF}_{(\mathrm{ABS})}$, increased $\mathrm{TR}_{0} / \mathrm{RC}$ and $\mathrm{ABS} / \mathrm{RC}$, and impaired photochemical and non-photochemical redox reactions (Fig. 6). Exogenous calcium reduced the values of $\mathrm{TR}_{0} / \mathrm{RC}, \mathrm{ABS} / \mathrm{RC}$, and $\mathrm{DI}_{0} / \mathrm{RC}$ to control levels, indicating that exogenous calcium enhanced electron transport capacity of stressed leaves, thereby relieving the hypoxia-mediated damage of cucumber leaves.

\section{Conclusions}

Hypoxic stress might impair the photosynthetic electron-transport chain from the donor side of PSII up to the reduction of end acceptors of PSI, thus limiting the production of reduction equivalents and the rate of $\mathrm{CO}_{2}$ assimilation. Exogenous calcium enhanced electron transport capacity and reduced hypoxic damage of cucumber leaves. We still need a further research to investigate what calcium dose mechanistically to cause all of this.

\section{Abbreviations}

ABS/RC: Absorption flux per $\mathrm{RC}$; $\mathrm{C}_{\mathrm{i}}$ : Intercellular $\mathrm{CO}_{2}$ concentration; $\mathrm{DI}_{\mathrm{o}} /$ $\mathrm{RC}$ : Dissipated energy flux per $\mathrm{RC}$ at $t=0$; DO: Dissolved oxygen; $\mathrm{ET}_{\mathrm{d}} d$ $\mathrm{RC}$ : Electron transport flux per $\mathrm{RC}$ at $\mathrm{t}=0 ; \mathrm{F}_{0}$ : Minimum fluorescence, when

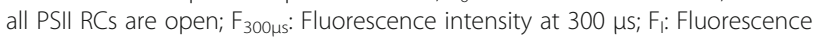
intensity at I-step (30 ms); Fj: Fluorescence intensity at J-step (2 ms); $F_{m}$ : Maximum fluorescence, when all PSII RCs are closed; Fv/Fm: Maximum quantum yield of PSIl; $g_{s}$ : Stomatal conductance; NPQ (=Fm/Fm'-1): Non-

photochemical quenching coefficient; OEC: Oxygen-evolving complex; $\mathrm{PI}$ : Performance index; $\mathrm{Pl}_{(\text {abs) }}$ : Performance index (PI) on absorption basis; $P_{\mathrm{n}}$ : Net photosynthetic rate; PPFD: Photon flux density; PSI: Photosystem I; PSII: Photosystem II; $Q_{a}$ : Primary quinone acceptor; $Q_{B}$ : secondary acceptor plastoquinone; qP: Photochemical quenching coefficient; RC: PSII reaction centre; RH: Relative humidity; ROS: Reactive oxygen species; Sm: Normalized total complementary are above the OJIP; $T_{r}$ : Transpiration rate; $T_{0} /$ $\mathrm{RC}$ : Trapped energy flux per RC at $t=0 ; \mathrm{V}_{\mathrm{t}}$ : Relative variable fluorescence at time t; WUE: Water use efficiency; $\varphi P_{0}$ : Maximum quantum yield of primary photochemistry at $\mathrm{t}=0$; DPSII: Actual photochemical efficiency of PSII

\section{Acknowledgments}

We thank Emma Tacken, PhD, from Liwen Bianji, Edanz Group China (http:// www.liwenbianji.cn/ac), for editing the English text of a draft of this manuscript.

\section{Funding}

This work was supported by the financially by the National Natural Science Foundation of China $(31401919,31471869)$ and Key Project of Science and Technology Commission of Shanghai (14DZ2282100). The funds Shanghai Agriculture Applied Technology Development Program, China (No. G2014070201) and the Young Talents Plan in Shang-Hai Agricultural System (Hu Nong Qing Zi No. 2016-1-10), which supported totally or in part the salaries of the students and researchers involved in the project and the materials. The authors declare that the research was conducted in the absence of any commercial or financial relationships that could be construed as a potential conflict of interest.

\section{Availability of data and materials}

The datasets generated and analysed during the current study are available from the corresponding author on reasonable request.

The seeds of plant material "Jinchun No. 2" were bought from Tianjin Kernel Cucumber Research Institute (Tianjin, China).

\section{Authors' contributions}

Conceived and designed the experiments: SG. Performed the experiments: LH, LY Analyzed the data: LH. Contributed reagents/materials/analysis tools: BL, ND. Wrote the paper: LH. All authors have read and approved the final version of the manuscript.

Ethics approval and consent to participate

Not applicable.

\section{Consent for publication}

Not applicable.

\section{Competing interests}

The authors declare that they have no competing interests. 


\section{Publisher's Note}

Springer Nature remains neutral with regard to jurisdictional claims in published maps and institutional affiliations.

\begin{abstract}
Author details
'Shanghai Key Lab of Protected Horticulture Technology, Horticultural Research Institute, Shanghai Academy of Agricultural Science, Shanghai 201106, China. ${ }^{2}$ Key Laboratory of Southern Vegetable Crop Genetic Improvement, Ministry of Agricultural, College of Horticulture, Nanjing Agricultural University, Nanjing 210095, China. ${ }^{3}$ College of Horticulture Shanxi Agriculture University, Taiqu 030801, Shanxi, China. ${ }^{4}$ Department of Horticulture, Henan Agricultural University, Zhengzhou 450000, Henan, China.
\end{abstract}

\section{Received: 20 March 2018 Accepted: 27 August 2018} Published online: 04 September 2018

\section{References}

1. Paul MV, lyer S, Amerhauser C, Lehmann M, van Dongen JT, Geigenberger P. Oxygen sensing via the ethylene response transcription factor RAP2.12 affects plant metabolism and performance under both normoxia and hypoxia. Plant Physiol. 2016;172(1):141-53.

2. Shabala S. Physiological and cellular aspects of phytotoxicity tolerance in plants: the role of membrane transporters and implications for crop breeding for waterlogging tolerance. New Phytol. 2011;190(2):289-98.

3. Shahzad Z, Canut M, Tournaire-Roux C, Martinière A, Boursiac Y, Loudet O, Maurel C. A potassium-dependent oxygen sensing pathway regulates plant root hydraulics. Cell. 2016;167(1):87-98.e14.

4. Yang CY, Hsu FC, Li JP, Wang NN, Shih MC. The AP2/ERF transcription factor AtERF73/HRE1 modulates ethylene responses during hypoxia in arabidopsis. Plant Physiol. 2011;156(1):202-12.

5. Pedersen O, Rich SM, Colmer TD. Surviving floods. Leaf gas films improve $\mathrm{O}_{2}$ and $\mathrm{CO}_{2}$ exchange, root aeration, and growth of completely submerged rice. Plant J. 2009:58(1):147-56

6. Shabala S, Shabala L, Barcelo J, Poschenrieder C. Membrane transporters mediating root signalling and adaptive responses to oxygen deprivation and soil flooding. Plant Cell Environment. 2014;37(10):2216-33.

7. Wang F, Chen ZH, Liu X, Colmer TD, Zhou M, Shabala S. Tissue-specific root ion profiling reveals essential roles of the CAX and ACA calcium transport systems in response to hypoxia in Arabidopsis. J Exp Bot. 2016;67(12):3747-62.

8. He L, Li B, Lu X, Yuan L, Yang Y, Yuan Y, Du J, Guo S. The effect of exogenous calcium on mitochondria, respiratory metabolism enzymes and ion transport in cucumber roots under hypoxia. Sci Rep. 2015;5:11391.

9. Zhu X, Dunand C, Snedden W, Galaud JP. CaM and CML emergence in the green lineage. Trends Plant Sci. 2015;20(8):483-9.

10. He L, Lu X, Tian J, Yang Y, Li B, Li J, Guo S. Proteomic analysis of the effects of exogenous calcium on hypoxic-responsive proteins in cucumber roots. Proteome Sci. 2012;10(1):42.

11. Yemelyanov W, Shishova MF, Chirkova TV, Lindberg SM. Anoxia-induced elevation of cytosolic Ca2+ concentration depends on different $\mathrm{Ca}^{2+}$ sources in rice and wheat protoplasts. Planta. 2011;234(2):271.

12. Subbaiah CC, Sachs MM. Molecular and cellular adaptations of maize to flooding stress. Ann Bot. 2003;91(2):119-27.

13. Wang YL, Zhang XF, Wang R, Bai YX, Liu CL, Yuan YB, Yang YJ, Yang SL. Differential gene expressiong analysis of 'chili' (pyrus bretschneideri) fruit pericarp with two types of bagging treatments. Horticulture Research. 2017:4:17005.

14. Rochaix JD. Assembly of the photosynthetic apparatus. Plant Physiol. 2011 155(4):1493-500

15. Jin H, Liu B, Luo L, Feng D, Wang P, Liu J, Da Q, He Y, Qi K, Wang J. Hypersensitive to high light1 interacts with low quantum yield of pnotosystem II 1 and functions in protection of photosystem II from photodamage in arabidopsis. Plant Cell. 2014;26(3):1213-29.

16. Yuan Y, Shu S, Li S, He L, Li H, Du N, Sun J, Guo S. Effects of exogenous putrescine on chlorophyll fluorescence imaging and heat dissipation capacity in cucumber (Cucumis sativus L.) under salt stress. J Plant Growth Regul. 2014;33(4):798-808.

17. Brestic M, Zivcak M, Kalaji HM, Carpentier R, Allakhverdiev SI. Photosystem II thermostability in situ: environmentally induced acclimation and genotypespecific reactions in Triticum aestivum L. Plant Physiol Biochem. 2012:57:93-105.

18. Qu C, Liu C, Gong X, Li C, Hong M, Wang L, Hong F. Impairment of maize seedling photosynthesis caused by a combination of potassium deficiency and salt stress. Environ Exp Bot. 2012;75:134-41.
19. Murchie EH, Lawson T. Chlorophyll fluorescence analysis: a guide to good practice and understanding some new applications. J Exp Bot. 2013;64(13): 3983-98.

20. Stirbet A. Govindjee. On the relation between the Kautsky effect (chlorophyll a fluorescence induction) and photosystem II: basics and applications of the OJIP fluorescence transient. J Photochem Photobiol B Biol. 2011;104(1-2):236-57.

21. Dodd AN, Kudla J, Sanders D. The language of calcium signaling. Annu Rev Plant Biology. 2010;61:593-620.

22. Yuan L, Shu S, Sun J, Guo S, Tezuka T. Effects of 24-epibrassinolide on the photosynthetic characteristics, antioxidant system, and chloroplast ultrastructure in Cucumis sativus L. under ca $\left(\mathrm{NO}_{3}\right)_{2}$ stress. Photosynth Res. 2012;112(3):205-14.

23. Li Q, Chen LS, Jiang HX, Tang N, Yang LT, Lin ZH, Li Y, Yang GH. Effects of manganese-excess on $\mathrm{CO}_{2}$ assimilation, ribulose-1,5-bisphosphate carboxylase/oxygenase, carbohydrates and photosynthetic electron transport of leaves, and antioxidant systems of leaves and roots in citrus grandisseedlings. BMC Plant Biol. 2010;10(1):42.

24. Smit MF, van Heerden PDR, Pienaar JJ, Weissflog L, Strasser RJ, Krüger GHJ. Effect of trifluoroacetate, a persistent degradation product of fluorinated hydrocarbons, on phaseolus vulgaris and zea mays. Plant Physiol Biochem. 2009:47(7):623-34.

25. Ma Y, Guo S. On different hypoxia tolerance of thirteen cucumber varieties. Jiangsu Agric Sci. 2004;5:68-70

26. Bradford MM. A rapid and sensitive method for the quantitation of microgram quantities of protein utilizing the principle of protein-dye binding. Anal Biochem. 1976;72(1):248-54

27. Kang YY, Guo SR, Li J, Duan JJ. Effect of root applied 24-epibrassinolide on carbohydrate status and fermentative enzyme activities in cucumber (Cucumis sativus L.) seedlings under hypoxia. Plant Growth Regul. 2009;57(3):259-69.

28. Lu C, Qiu N, Wang B, Zhang J. Salinity treatment shows no effects on photosystem II photochemistry, but increases the resistance of photosystem II to heat stress in halophyte Suaeda salsa. J Exp Bot. 2003;54(383):851-60.

29. Strasserf RJ, Srivastava A. Polyphasic chlorophyll a fluorescence transient in plants and cyanobacteria. Photochem Photobiol. 1995;61(1):32-42.

30. Han S, Tang N, Jiang HX, Yang LT, Li Y, Chen LS. CO2 assimilation, photosystem \| photochemistry, carbohydrate metabolism and antioxidant system of citrus leaves in response to boron stress. Plant Sci. 2009;176(1):143-53.

31. Rollins JA, Habte E, Templer SE, Colby T, Schmidt J, von Korff M. Leaf proteome alterations in the context of physiological and morphological responses to drought and heat stress in barley (Hordeum vulgare L.). J Exp Bot. 2013;64(11):3201-12

32. van Dongen JT, Schurr U, Pfister M, Phloem Metabolism GP. Function have to cope with low internal oxygen. Plant Physiol. 2003;131(4):1529-43.

33. He L, Guo S, Lu X, Wang L, Yang Y. Effects of calcium on soluble protein expression of cucumber seedlings under roo-zoon hypoxia stress. Journal of Nanjing Agricultural University. 2012;35:21-5.

34. Gorbe E, Calatayud A. Applications of chlorophyll fluorescence imaging technique in horticultural research: a review. Sci Hortic. 2012;138:24-35.

35. Ryan KG, Tay ML, Martin A, McMinn A, Davy SK. Chlorophyll fluorescence imaging analysis of the responses of Antarctic bottom-ice algae to light and salinity during melting. J Exp Mar Biol Ecol. 2011;399(2):156-61.

36. Mehta P, Jajoo A, Mathur S, Bharti S. Chlorophyll a fluorescence study revealing effects of high salt stress on photosystem II in wheat leaves. Plant Physiol Biochem. 2010:48(1):16-20.

37. Hayat S, Hasan SA, Yusuf M, Hayat Q, Ahmad A. Effect of 28homobrassinolide on photosynthesis, fluorescence and antioxidant system in the presence or absence of salinity and temperature in Vigna radiata. Environ Exp Bot. 2010;69(2):105-12.

38. Shu S, Tang Y, Yuan Y, Sun J, Zhong M, Guo S. The role of 24epibrassinolide in the regulation of photosynthetic characteristics and nitrogen metabolism of tomato seedlings under a combined low temperature and weak light stress. Plant Physiol Biochem. 2016;107:344-53.

39. Bhattacharyya D, Gnanasekaran P, Kumar RK, Kushwaha NK, Sharma VK, Yusuf MA, Chakraborty S. A geminivirus betasatellite damages the structural and functional integrity of chloroplasts leading to symptom formation and inhibition of photosynthesis. J Exp Bot. 2015;66(19):5881-95.

40. Strasser RJ, Tsimilli-Michael M, Srivastava A. Analysis of the chlorophyll a fluorescence transient. In: chlorophyll a fluorescence: A signature of photosynthesis. Edited by Papageorgiou GC, Govindjee. Dordrecht: Springer Netherlands; 2004: 321-362. 
41. Srivastava A, Guissé B, Greppin H, Strasser RJ. Regulation of antenna structure and electron transport in photosystem II of pisum sativum under elevated temperature probed by the fast polyphasic chlorophyll a fluorescence transient: OKJIP. Biochimica et Biophysica Acta (BBA) Bioenergetics. 1997;1320(1):95-106.

42. Aro EM, McCaffery S, Anderson JM. Photoinhibition and D1 protein degradation in peas acclimated to different growth irradiances. Plant Physiol. 1993;103(3):835-43.

Ready to submit your research? Choose BMC and benefit from:

- fast, convenient online submission

- thorough peer review by experienced researchers in your field

- rapid publication on acceptance

- support for research data, including large and complex data types

- gold Open Access which fosters wider collaboration and increased citations

- maximum visibility for your research: over $100 \mathrm{M}$ website views per year

At BMC, research is always in progress.

Learn more biomedcentral.com/submissions 